\title{
Rolf Mantel and the Computability of General Equilibria: On the Origins of the Sonnenschein-Mantel-Debreu Theorem
}

\author{
Fernando Tohmé
}

General equilibrium theory (GET) took the entire edifice of economic theory by storm during the 1950s. Its elegant existence theorems, proved by, among others, Kenneth Arrow and Gerard Debreu (1954) and Lionel McKenzie (1959), provided a framework of analysis that made more precise and sound the main intuitions of the neoclassical school. An even more important consequence of these developments may be that they set a new and higher standard of mathematical sophistication in economics. A remarkable aspect of this new standard was its nonconstructive flavor, pretty much in consonance with the postwar predominance of Bourbakian mathematics.

The central role of GET in economics as the backbone of the mainstream is still uncontested. But its primacy as an all-encompassing theory of economic phenomena was challenged at its very inception, because of its inability to yield proofs of uniqueness and stability of equilibria from general characterizations of preferences and technologies. This lack of results, however, did not shake the pervasive use of neoclassical frameworks in which a system of competitive prices was seen as embodying all the relevant information in the economy. This tranquilizing belief

I wish to thank Ana Martirena-Mantel for her kind help, which greatly improved the quality of this article. Of course, all the errors and inaccuracies are my own responsibility. The research presented here was supported by ANPCyT-FONCyT (grant 13319) and SeCyTUniversidad Nacional del Sur (24/E044).

History of Political Economy 38 (annual suppl.) DOI 10.1215/00182702-2005-023

Copyright 2006 by Duke University Press 
suffered a heavy blow from the papers of Hugo Sonnenschein (1973), Rolf Mantel (1974), and Debreu (1974). They showed that the only properties that can be predicated on aggregate excess demand (which in turn characterizes the competitive equilibria) are continuity, homogeneity of degree zero, and the validity of Walras's law. Other than that, as Andreu MasColell, Michael Whinston, and Jerry Green $(1995,598)$ say, "anything goes." These results show that for every given system of equilibrium prices and its associated excess demands, an arbitrary economy can be defined, exhibiting the same aggregate behavior and the same equilibria. That is, prices do not convey all the relevant information about the economy, since a "mock" one is able to generate the same aggregate demand.

One of the authors of this result was Mantel. By 1974 he was a professor of economics at the Universidad de Buenos Aires, in Argentina. His seminal paper stems from research done in solitude in Argentina after finishing his PhD at Yale in 1965. Unlike Sonnenschein or Debreu, Mantel drew many of his intuitions from his work on computability of equilibria and particularly from his experience in programming a computer planning system for the Argentinian government in 1971.

My goal in this article is to show how Mantel's approach to GET was driven by a completely different family of concerns than those that guided the work of all other theorists associated with him in the proof of the "anything goes" result. Surprising as it may seem, he intended at that time to tightly connect economic theory and practice, particularly in the field of policymaking. I argue that this explains why he was so concerned, as it will be seen, with computational approaches and did not quite follow the Bourbakian path. Another interesting aspect of Mantel's motivations is that his research on the properties and computability of equilibria was for him just a component of his wider research agenda on the problem of economic development.

The inevitable conclusion that Mantel drew from his own results was that some sort of idiosyncratic "social" information is needed to compute the relative prices that ensure an efficient use of resources in a competitive market. Furthermore, this was for him a particularly pressing issue, since any committed policymaker has to take into account those social aspects in the design of market institutions intended to promote economic development.

In section 1 I discuss how Mantel's training in Argentina at the turn of the 1960s gave him a view of economics in which theory had to be driven by the requirements of the real world, and in particular by the goal of 
inducing economic development in the country. In section 2 I discuss how this vision was initially informed at Yale by his encounters with computation and later, back in Argentina, further elaborated in the light of Mantel's work for a planning agency. I claim that this vision inspired his 1974 paper. In section 3 I discuss the status of the problem of characterizing excess demand during the 1960s and early 1970s. Finally, in section $4 \mathrm{I}$ discuss the conclusions that Mantel drew in his final years from his earlier results.

\section{Mantel's Background: Economics in Argentina at the End of the 1950s}

Rolf Ricardo Mantel was born in 1935 to a middle-class family of Swiss and German descent. Enrolling in the Universidad de Buenos Aires in 1954 , he intended to pursue a program in accountancy. He saw it as a way to combine his interest in economic issues and his prowess in mathematics while pursuing a profession.

In those days no program in economics existed at any of the universities in Argentina. ${ }^{1}$ The School of Economic Sciences in Buenos Aires had, of course, many economists among its faculty, but no organized system of research or teaching in the field existed in the early 1950s. Moreover, most of those economists were amateurs (being originally lawyers or engineers). At that particular moment, older professors who had adequate training in the neoclassical tradition had retired without leaving followers. Most of them were disciples of Hugo Broggi, who did his doctorate under David Hilbert in Göttingen and was a close follower of Vilfredo Pareto. Broggi's influence lead to an incipient interest in theoretical research, José Barral Souto being of particular interest here, since he analyzed in 1941 the notion of comparative advantages using linear inequations, quite unaware of the transition in mathematical economics from calculus-based to convex-analytic methods that was happening at the time.

The only new figures in academic economics were part of an influential group of Central and Eastern European exiles who found refuge in Juan Perón's Argentina. Many of them had been appointed in proGerman governments in Europe during World War II. Among them were

1. The information about the history of economics in Argentina is drawn from Fernández López 2001. 
Stefan Cottely, former head of Hungary's National Bank, and Florin Manoliu, former subsecretary of Romania's ministry of oil. Many had a more academic outlook, like Oreste Popescu and Lascar Saveanu of Romania and Uros Bacic from Croatia. They all exhibited a strong historicist bent and were active in designing the future programs and academic departments in economics in several universities outside Buenos Aires. Interestingly enough, these foreign scholars stimulated interest in the analysis of the problems of development and policymaking for the Argentinian economy. They introduced into the rather amateurish style of economics of the time a certain patina of Old World scholarship, thus changing the overall outlook of the discipline in the country. ${ }^{2}$

By 1958 a proper program in economics was created at the Universidad de Buenos Aires, and Mantel enrolled, already interested in the intellectual challenges of the discipline and rather bored of accountancy. This program, which led to a degree in political economy (in the older usage of the expression), heavily emphasized the applied side, particularly the development and policy problems of Argentina. Mantel excelled, exhibiting all his talents, being the more mathematically oriented of a group of enthusiastic budding scholars. In this group was also his future wife, Ana Martirena, ${ }^{3}$ as well as other economists who became influential in the next decades. They convened once a week, under the informal direction of Julio H. G. Olivera, a few years their elder. Olivera was originally a lawyer who became one of the main proponents of the "Latin American" version of structuralism. He introduced serious standards of research, emphasizing mathematical rigor in the analysis of economic issues. Olivera saw immediately that Mantel had enormous potential and encouraged him to pursue an academic career, and particularly to get a doctoral degree abroad.

In those years, Mantel became interested in the possibility of using economic theory as a foundation for designing policies to promote the rapid development of the country. As he would later say, "Every problem I cared for concerned economic development." ${ }^{4} \mathrm{He}$ already clearly dis-

2. The name of Raul Prebisch is, of course, familiar in the history of economic development. But most of the work he did in Argentina was as a public servant, and the ideas for which he is better known, promoted by the United Nations' Economic Commission for Latin America, were developed during his exile in Chile in the late 1940s.

3. Rolf and Ana Martirena-Mantel coauthored many papers on international economics, the topic on which Ana did her PhD work at Yale.

4. All unreferenced remarks attributed here to Mantel are my own personal recollections from the time when I was doing my doctorate under him. 
tinguished the mathematical method in economics from the content, which he thought had to be motivated by real-world problems. For example, he had a vision about the unavoidability of economic policy and consequently about the state's role in less-developed economies: ${ }^{5}$

In the contemporary world, the state has an enormous gravitational pull over the economy of a country, making it impossible to demand from it a "neutral" behavior, in the liberal sense. Practical solutions to this problem are manifold, going from the extreme of collectivist solutions, in which the intertemporal preferences of the state substitute for individual ones, to the alternative of more or less random governmental programs created in response to fiscal needs. (Mantel 1999b, 23)

Despite such clear statements, his view of economics always seemed too distant from the earthly concerns not only of laymen but also of some of his colleagues. ${ }^{6}$

The reason for the gap between Mantel and other (most, in fact) Argentinian economists is that they could not see that he shared their interests and that a fruitful interaction could easily arise if his formal outlook were understood. Of course, he would always be a theoretician, but his preoccupation with the design of the right tools to facilitate economic development was at the center of his academic work.

At the beginning of the 1960s he and his wife got grants from the Organization of American States (OAS) to pursue PhDs at Yale. Some topics he studied before leaving, particularly the problem of optimal development and of the design of stabilization policies, were later revisited by him, in light of his new training.?

\section{Mantel and the Computation of Equilibria}

Yale was an exhilarating academic experience for Mantel. He became a huge fan of Irving Fisher, a local hero, who had tried to build (but never

5. Here and throughout, all translations of the original Spanish version are my own.

6. In 1993 Mantel won a much-coveted prize in Argentina, the Bunge \& Born prize. This made him, for a very short period, a celebrity quoted even in TV soaps. Asked by journalists about the future value of the exchange rate, he drily answered that it was not a question of economics but of psychology, given that it all depended on the mood of the economy minister, Domingo Cavallo. He elaborated a little bit, saying that economics can only predict the outcome of rational behavior. It is uncertain whether the journalists understood that this was a sarcasm and not just an academic statement.

7. See, for example, his 1999 b and 1999 e papers. 
completed) an analog computer to calculate equilibrium prices in a competitive economy. ${ }^{8}$ Interested in addressing the same problem, which accorded with the interests of the Yale-based Cowles Commission, Mantel asked Tjalling Koopmans, who was on his prospectus committee (Michael Montias was the other member) to be his thesis adviser. Although Koopmans accepted, he was on leave for a while. Mantel changed then to Herbert Scarf, fresh from his success in showing in 1960 that competitive economies may not have stable equilibria. The dissertation committee, however, also included Koopmans, back at Yale, and Menahem Yaari.

Beyond his interest in computing equilibria, Mantel developed an overall fascination with computers from his encounters with the IBM mainframes of Yale's computer lab. Always a constructivist, he wanted his theoretical constructions to be backed up by strong evidence. Moreover, he was not willing to accept his own results if they could not be tested numerically. The computers allowed him to run complicated numerical experiments that were too hard to do by hand. He learned to program with punched cards and using the amazingly small RAMs of the computers of that time. This interest in computers was lifelong, and Mantel later became one of the most dedicated users of computer models among the economists of Argentina.

Mantel's Yale thesis, finished in 1965 and published in 1968, introduced an algorithm for computing equilibria through successive approximations, without making any direct use of fixed-point theorems. His goal was to provide an alternative, constructive, form to prove the existence of equilibrium without having to go through the use of results like Kakutani's theorem. Furthermore, if such an algorithm were available, it would be possible to predict future outcomes and determine policies to guide the economy.

I got interested in the problem of calculating equilibria ten years after the publication of the proof of their existence in the Walrasian model by Arrow and Debreu. I had to choose a topic for my dissertation. Kakutani's theorem, on which Arrow and Debreu based their proof, allows one to affirm that a solution exists, but it gives no indication on how to calculate it. Therefore, even if that step forward showed that it could

8. Mantel's admiration for Fisher was not without a certain "Yale pride." In his acceptance talk at his incorporation to the National Academy of Economic Sciences of Argentina, he mentioned the fact that Fisher was the first president of the Econometric Society and that the relocation of the Cowles Commission from Chicago to Yale should be seen as a tribute to Fisher (Mantel 1985). 
be interesting to apply that model to practical issues, it was still not possible to do that effectively, since solutions could be calculated only for already well-known special cases.

I came up with the idea of looking for a different, constructive, form to prove the existence of a solution, which at the same time would calculate the equilibrium. In time this model could be used to determine economic policies and predict the future of the economy. ...

My research was not fruitless, because, as a subproduct, it led to the first method to calculate solutions for Walrasian models. . . . I looked for a way to calculate equilibrium prices up to a given low margin of error. If the supply function has a decreasing section, something that, as it is well known, may for instance happen in the labor market, it is easy to see that there might exist many price systems for which supply and demand are almost coincident. It is always possible to conceive sufficiently irregular curves that intersect at any point farther away from the ones already represented. The only measure of "closeness" between the curves is just the difference between supplied and demanded amounts. ... Any practical algorithm has to take into account such measure in order to decide when a point has been reached that for all possible purposes may play the role of an equilibrium. (Mantel 1985, $25,26,27,28$ )

Back in Argentina, Mantel became a professor and a researcher at the National Council of Research (an agency that funded part of his $\mathrm{PhD}$ program at Yale). A couple of years later, a former professor, Javier Villanueva, who was in charge of a recently created National Council of Development, hired him, giving Mantel the freedom to pursue his dream of using computers to determine policies to promote economic development. He implemented to a certain extent his own algorithm, although with substantial changes because of the requirement he imposed on himself that the planning program had to be validated and calibrated with real-world data.

The present state of both the science of economics and the art of computing does no longer justify the mere verbal and qualitative analysis of complex economic systems, based only in making explicit a few variables. ... Our discipline resembles a bit meteorology, where longterm prediction is extremely hard. But, like that science which, mostly thanks to the advances in computation and the enormous amount of money devoted to amass basic information, is now able to save lives 
thanks to its forecasts of severe atmospheric disturbances, in economics we might be able to indicate the most probable effects of economic policies and improve the situation of a country.

The theory of economic policymaking is a branch of decision theory. The latter analyzes the elements that must be considered by the agent responsible for making the decision-in our case the planner-in order to determine the optimal action in a rational way.... The scarce resources of the organism in charge of the design of the plan may be better spent by focusing on the technical problem of finding an efficient plan [instead of an optimal one]. That is, once the relevant variables are determined, the goal should be to find a plan in which the degree in which any goal is attained cannot be improved without lowering the attainment of another goal. ...

These ideas began to be implemented in our country. In 1971 the author was hired by the Secretary of the National Council of Development to prepare a planning model.... This system consists of a series of computer programs that allow an efficient use of the available information as well as an adequate interaction between the computer and the human staff. ...

The second variant does not require an explicit welfare function but the direct interaction with a policymaker, who might indicate at each iteration a direction of preferences and determine the optimal level by observing the rates of substitution among the attainment degrees of the goals of the plan. (Mantel 1999f, 163, 167, 170, 172)

One of the customary coups in Argentina at that time ended this project. But it left Mantel with many problems to think about. One was determining the minimal requirements of information for computing equilibrium. Although this was motivated by a concrete problem, he saw its theoretical content immediately. He discovered that, even if he wanted to avoid the use of fixed-point theorems, hidden in his algorithm was a procedure that ended up minimizing the gap between demand and supply functions, which worked only in those cases in which Brouwer's or Kakutani's theorems could be applied. An interesting aside of this development is that Scarf realized immediately that Mantel's algorithm did more than approximate equilibria. He began his own research and published an influential book on the subject in 1973, as Mantel $(1985,28,29)$ acknowledges:

Regrettably, I did not realize that I was asking the wrong question. I looked for a method for approximating the solution and this is not 
possible in general. Scarf asked the right question and today the algorithm carries his name. . . Scarf understood that what matters is not whether the solution found by the algorithm is close to the true one. It suffices to find prices for which supply and demand are almost equal.

In Scarf's book little mention is made of Mantel's result. Mantel resented this, although, as the previous quote indicates, he always credited Scarf for realizing that a close relation exists between algorithms to compute equilibria and mathematical fixed-point theorems. This realization led Mantel to think about how unavoidable those mathematical results are and their relation with the overall information carried by equilibria.

\section{The Characterization of Aggregate Excess Demand}

The connection between his algorithm and Kakutani's theorem triggered Mantel's interest in determining whether there could exist equilibria in competitive markets that do not obtain as fixed points. A partial answer to this question was given by Hirofumi Uzawa (1962), who claimed that the existence of a Walrasian equilibrium implies Brouwer's (and by extension Kakutani's) theorem.

While preparing his Yale thesis, Mantel was already aware of Uzawa's result. But at that time he thought it was highly dependent on assuming that global demand and supply functions were continuous, homogeneous of degree zero, and obeyed Walras's law. Mantel (1985, 26-27) felt that this characterization was excessively restrictive:

From a logical point of view, the existence of a solution for the Walrasian model is equivalent to the existence of a fixed point of transformations that verify the hypotheses of Kakutani's theorem, in the sense that the existence of equilibrium can be proved on the basis of this theorem, and, conversely, it is possible to prove Kakutani's theorem up from the hypothesis of the existence of a competitive equilibrium in the Walrasian model, independently of the functional relations that can be adopted.

This last equivalence had been proved by Hirofumi Uzawa a few years before [Mantel's work on his dissertation], but at that time it was unclear whether the supply and demand functions used by him, i.e., arbitrary functions except of being continuous, homogeneous of degree zero, and satisfying Walras's law, could be obtained by aggregation up 
from individual demand functions obtained from the maximization of preferences and individual supply functions resulting from the maximization of profits by producers.

In fact, he had already found instances of excess demand functions that did not satisfy those properties, as for example in the case of the interaction among economies in which factors can move freely from one to another:

In 1967 Dr. Mantel extended the theorem of no equivalence [between equilibria in international trade under free trade and perfect factor mobility], pointing out that the existence of equilibrium under free trade cannot be replicated in the free mobility case since there can exist discontinuities ("holes" according to his expression) in the aggregate excess demand functions. (Olivera 1999, vi)

On the other hand, he felt that in all cases in which he could apply his algorithm, the excess demand functions were precisely continuous, homogeneous of degree zero, and satisfied Walras's law.

Then Mantel read Sonnenschein's (1973) paper in which it was conjectured that those properties were the only ones that could be derived for generic excess demand functions. Sonnenschein used the argument that any polynomial function with these properties could be decomposed in a number of functions that may arise from the maximization of preferences by individual consumers. This is interpreted as that, for any excess demand function that is continuous, homogeneous of degree zero, and obeys Walras's law, there can be found an economy in which this function arises from the maximization of individual preferences. The problem with Sonnenschein's construction is that the number of individuals in the economy depends on the degree of the polynomial excess demand function.

Mantel was more than aware of the implications of this work. In fact, he readily produced a construction that generalized Sonnenschein's. Before presenting Mantel's result, I introduce some previous definitions.

Assume an economy of $n$ commodities, in which prices are trimmed by $\varepsilon$ (more precisely, for each $1 \leq j \leq n, \varepsilon \leq p_{j} \leq[1 /(\varepsilon)]$, where $p_{j}$ is a price of $\operatorname{good} j) . F^{n}(\varepsilon)$ is the space of functions with range $\mathfrak{R}^{n}$ and domain the space of $\varepsilon$-trimmed prices. Assume that each $f \in F^{n}(\varepsilon)$ verifies the following:

1. Continuity.

2. Homogeneity: $f(\lambda p)=f(p)$ for every $\varepsilon$-trimmed vector of prices $p$ and for every $\lambda>0$.

3. Walras's law: $p \cdot f(p)=0$ for all $\varepsilon$-trimmed vectors of prices $p$. 
An excess demand $f$ is said to be generated by an economy with $n$ commodities, if there exists a certain number of individuals, $1, \ldots, K$ such that each individual excess demand function $f_{k}$ of an individual $k$ arises maximizing $u^{k}(x)$ over the budget constraint $p \cdot x \leq p \cdot \omega^{k}$, then $f(p)=\sum_{k=1}^{K} f^{k}(p)$ for every $\varepsilon$-trimmed vector of prices $p$. Let $G^{n}(\varepsilon)$ be the set of all the market excess demand functions generated by an $n$ commodities economy in this way. Finally, let $L^{n}(\varepsilon)$ be the space of continuously differentiable functions with range $\Re^{n}$ and domain the space of $\varepsilon$-trimmed prices that verify a mild Lipschitz condition on the first derivative, namely, that for each $g \in L^{n}(\varepsilon)$ there exists a constant $K$ such that

$$
g(p)+\frac{\partial g}{\partial p}(p) \cdot(q-p) \leq g(q)+K|p-q|^{2}
$$

where $p$ and $q$ are $\varepsilon$-trimmed prices.

Then Mantel (1974) states the following:

Theorem 1. For all $\varepsilon>0, F^{n}(\varepsilon) \cap L^{n}(\varepsilon) \subset G^{n}(\varepsilon)$. Furthermore, the set of pure trade $n$ commodities economies can be restricted to have at most $2 n$ consumers.

What is interesting for our argument is how Mantel proved this claim. He constructs an economy with $2 n$ consumers; the first $n$ have sort of "CobbDouglas" utility functions, with demands satisfying the strong axiom of revealed preference. Adding their excess demands and subtracting from a given $f \in F^{n}(\varepsilon)$, the remainder can be seen as the sum of the excess demands of the other $n$ consumers, which also satisfy the strong axiom of revealed preference.

His proof was typical of his work: constructive and easily verifiable. In fact, it shows his idiosyncratic style of mathematical argumentation, which he deemed "experimental mathematics." That is, before proving the claim he tried to find either an example or a counterexample. In both cases, it had to show clearly why the claim was true or false. This nonBourbakian type of mathematical work was more like the approach of a computer scientist than that of an economist. In any case, the paper is extremely constructive and can be easily followed with an understanding of how to add and subtract differentiable functions.

Later that same year, Debreu was able to prove that $F^{n}(\varepsilon) \subset G^{n}(\varepsilon)$ in economies with just $n$ consumers, which is the definitive claim as known today. For Mantel's goal of finding a computational non-fixed-point argument of the existence of equilibrium, this was a heavy blow, since it showed that Uzawa's result was generic. 
Hugo Sonnenschein conjectured that microeconomic theory does not put constraints on the shape of the aggregate demand function, except for the aforementioned properties. He showed this for the case of a special family of functions. Later the author could show that this is so in much more general cases. As for many other topics, the last word was Debreu's, who proved the complete equivalence. With these investigations a full proof was given for Uzawa's claim that the mathematical problem of Kakutani and the economic one of Walras are equivalent from the logical point of view.

It took me time to realize that I was looking for something we now know it cannot be obtained. There are no methods to calculate equilibrium solution that do not also yield a fixed-point result. (Mantel 1985, 27)

Even so, Mantel was glad to settle this question, since this result also meant that fixed-point arguments could be computationally implemented, a useful outcome in terms of the potential applications he had in mind:

It is regrettable that the abundant work on this topic [applied general equilibrium] does not include Argentinian examples, despite the fact that the techniques are well known here since their very inception. ... Let us hope that this situation will change in the future and these new methods will be applied to determine economic policies to ensure the progress and welfare of Argentina. (331)

\section{Mantel and the Limitations of General Equilibrium Theory}

What were Mantel's own ideas about the consequences of his results? Besides the terse mentions in a couple of printed works, he was very careful with his public expressions, but in private he held two interesting ideas. One was that something, highly relevant for determining economic outcomes, is missing in the theoretical characterization of an economy. Moreover, Mantel contended that many of the usual assumptions in GET are just crude mathematical proxies for real-world properties. He felt, for example, that assuming an invariant structure of preferences was something that economic theory would dispose of sooner or later:

In the field of optimal growth theory, since Ramsey's time it is frequent ... [to assume] a constant rate of preference. Such an optimality criterion implies that preferences are independent over time. Follow- 
ing in the tradition of Irving Fisher [Mantel] . . showed that there exist welfare functions for which the ... preferences are variable. (Mantel 1999c, 331) ${ }^{9}$

His other idea was highly influenced by his experience as a professor of both economic policy and Marxist economics at the Universidad de Buenos Aires. Taught in the heyday of political turmoil and popular sympathy for left-wing policies, his courses were seen as "rightist" by radical students who despised his formal approach. ${ }^{10}$ In the almost empty classrooms in which he taught, he concentrated on the computational aspects of the subjects. Drawing on his own experience in the design of the planning system, he claimed that no matter which political leaning they could have, economic policies must always take into account the political, social, and institutional aspects of the economy:

Economics is a social science, and as such it analyzes part of the behavior of societies. ... Economic theory seeks systematic explanations for all the aspects of the phenomena of production, distribution, and consumption of goods and services. The theory of economic policies intends to determine the means to control the economic process in order to improve the allocation of resources in those activities. (Mantel 1999f, 166-67)

While this may sound like a platitude, Mantel considered seriously how to incorporate these items in his planning system. He readily acknowledged that these factors reduce drastically the number of alternative outcomes and prices. This reduction in degrees of freedom has a good side: it is no longer easy to find a "mock" economy.

The bottom line of Mantel's ideas is that fully characterizing the information in an economy requires, contrary to the assumptions of methodological individualism, incorporating factors not held by any agent but by the economy as a whole. Prices are just part of that picture, but not enough to yield a complete panorama of the economy:

9. He used time-varying preferences to explore a problem that he thought was urgent to solve: how to ensure economic growth with equality (Mantel 1995, 1999c).

10. Curiously enough, after being attacked by the Left, he was reprimanded a little later by a right-wing chancellor of the Universidad de Buenos Aires for not "properly reporting" to the authorities about the purpose of a trip to Harvard in which he finished a paper (1974) in the same vein as McFadden, Mas-Colell, Mantel, and Richter 1974. Mantel's overall experience at the university was quite negative. He bitterly resigned in 1985 after a series of offenses, which he poignantly described in a letter to the newspaper Clarin (Buenos Aires) on 20 December of that year. 
To determine optimal economic policies there are three fundamental elements. In the first place a description of the economic system. . . . In second place a social welfare relation that allows [a planner] to evaluate goals.... In the third place, it is necessary to know the limits which constrain how variables may change without losing their meaningfulness for both the model and the social preferences. (Mantel 1999d, 229-30)

It is clear that it was troublesome for someone trained in the Cowles tradition but with a strong computational bent to see how to design a model with all the desired properties. Even so, Mantel sought in many ways, always using his mathematical experiments (both by hand and by computer), to find better economic models, able to explain and predict at the same time. His numerous papers written in Spanish, in which he applied this approach to analyzing the troubled Argentinian economy, show how deeply he felt about the appropriate method of economic argumentation.

Always prone to revisit his work of the 1970s, he made his last attempt at that in 1995 (Mantel 1999a). There, the constructivity of his approach and the connections with his planning system are evident. His goal in this last work was to find a mock economy of $n$ Leontief agents from a limited number of observations of the aggregate demand. The idea, of course, was to find ways to rationalize real-world data. Instead of seeking the real economy, he had to look for a good approximation because of the lack of enough information. The goodness of fit would help, like in his computer system of 1971, calibrate the properties of the mock economy.

Mantel died in 1999, before knowing that some authors questioned the general validity of the proofs of Sonnenschein's conjecture (e.g., Chiappori and Ekeland 1999). He would have disagreed with them, because he felt that the result was consistent with other aspects of economic theory. In any case, he preferred to use whatever he had at hand to attack more worldly and pressing problems. The final balance is that the computational economist won out over the theorist.

\section{References}

Arrow, K., and G. Debreu. 1954. Existence of Equilibrium for a Competitive Economy. Econometrica 22:265-90.

Chiappori, P., and I. Ekeland. 1999. Aggregation and Market Demand: An Exterior Differential Calculus Viewpoint. Econometrica 67:1435-57.

Debreu, G. 1974. Excess Demand Functions. Journal of Mathematical Economics $1: 15-21$. 
Fernández López, M. 2001. La ciencia económica Argentina en el siglo XX. Estudios económicos, n.s., 18:1-30.

Mantel, R. 1968. Towards a Constructive Proof of the Existence of Equilibrium in a Competitive Economy. Yale Economic Essays 8:155-96.

- 1974. On the Characterization of Aggregate Excess Demand. Journal of Economic Theory 7:348-53.

- 1985. El papel de la matemática en la economía contemporánea. Documentos de Trabajo 50, Centro de Estudios Macroeconómicos, Buenos Aires.

— 1995. Why the Rich Get Richer and the Poor Get Poorer. Estudios de economía 22:177-205.

1999a. Agregación de bienes perfectamente complementarios. Economica

(La Plata) 45.2:299-317.

—. 1999b. Criterios de desarrollo óptimo. Economica (La Plata) 45.2:23-39.

—. 1999c. Optimal Economic Growth with Recursive Preferences: Decreasing Rate of Time Preference. Economica (La Plata) 45.2:331-48.

_. 1999d. Planes óptimos con preferencias desconocidas. Economica (La Plata) 45.2:229-42.

— 1999e. Políticas de estabilización económica. Economica (La Plata) 45.2:93119.

—. 1999f. La utilización de modelos formales para la planificación económica. Economica (La Plata) 45.2:163-78.

Mas-Colell, A., M. D. Whinston, and J. R. Green. 1995. Microeconomic Theory. New York: Oxford University Press.

McFadden, D., A. Mas-Colell, R. Mantel, and M. Richter. 1974. A Characterization of Community Excess Demand Functions. Journal of Economic Theory 9:361-74.

McKenzie, L. 1959. On the Existence of General Equilibrium for a Competitive Market. Econometrica 27:54-71.

Olivera, J. H. G. 1999. Proemio. Economica (La Plata) 45.2:v-vi.

Scarf, H. 1960. Some Examples of Global Instability of the Competitive Equilibrium. International Economic Review 1:157-72.

1973. The Computation of Economic Equilibria. New Haven, Conn.: Yale University Press.

Sonnenschein, H. 1973. Do Walras' Identity and Continuity Characterize the Class of Community Excess Demand Functions? Journal of Economic Theory 6:345-54.

Uzawa, H. 1962. Walras' Existence Theorem and Brouwer's Fixed Point Theorem. Economic Studies Quarterly 12:59-62. 